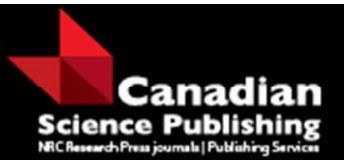

Canadian Journal of Forest Research Revue canadienne de recherche forestière

\title{
Fine Root Biomass Declined in Response to Restoration of Soil Calcium in a Northern Hardwood Forest
}

\begin{tabular}{|r|l|}
\hline Journal: & Canadian Journal of Forest Research \\
\hline Manuscript ID & cjfr-2015-0434.R1 \\
\hline Manuscript Type: & Article \\
\hline Date Submitted by the Author: & 21-Jan-2016 \\
\hline Complete List of Authors: & $\begin{array}{l}\text { Fahey, Timothy; Cornell University, Natural Resources } \\
\text { Heinz, Alexis; Cornell University, Natural Resources } \\
\text { Battles, John; University of California Berkeley, Environmental Science } \\
\text { Policy and Management } \\
\text { Fisk, Melany; Miami University, Department of Biology } \\
\text { Driscoll, Charles T.; Syracuse University } \\
\text { Blum, Joel; University of Michigan } \\
\text { Johnson, Chris; Syracuse University }\end{array}$ \\
\hline Keyword: & acidification, allocation, leaf area index, mycorrhizae, production \\
\hline & \multicolumn{2}{|l}{} \\
\hline
\end{tabular}


1

3

4 AUTHORS: Timothy J. Fahey ${ }^{1}$, Alexis K. Heinz ${ }^{1}$, John J. Battles ${ }^{2}$, Melany C. Fisk ${ }^{3}$, 5 Charles T. Driscoll ${ }^{4}$, Joel D.Blum ${ }^{5}$ and Chris E. Johnson ${ }^{4}$

6

$8{ }^{1}$ Department of Natural Resources, Cornell University, Fernow Hall, Ithaca, NY

914853 (tjf5@cornell.edu; akh24@cornell.edu)

$10{ }^{2}$ Department of Environmental Science, Policy and Management (E.S.P.M.),

11 University of California at Berkeley, Berkeley, CA, USA 94720--3114

$12{ }^{3}$ Miami University, Department of Biology, Oxford, OH 45056

13 (fiskmc@miamioh.edu);

$14{ }^{4}$ Department of Civil and Environmental Engineering, Syracuse University, Link

15 Hall, Syracuse, NY 13244 (ctdrisco@syr.edu, cejohns@syr.edu);
CORRESPONDING AUTHOR: Timothy J. Fahey ${ }^{1}$ - tjf5@cornell.edu Arbor, MI 48109 (jdblum@umich.edu)

$$
\begin{gathered}
\text { Fine Root Biomass Declined in Response to Restoration of Soil Calcium in a } \\
\text { Northern Hardwood Forest }
\end{gathered}
$$


Abstract

24 Forest health deteriorated in eastern North America as a result of depletion of

25 available soil base cations by elevated inputs of acid deposition. We

26 experimentally restored available calcium to soils of a forested watershed at

27 Hubbard Brook, New Hampshire and measured the response of fine root biomass

28 fourteen years after treatment. In this northern hardwood forest fine root $(<1$

$29 \mathrm{~mm}$ diameter) biomass declined significantly in response to the Ca addition

30 treatment relative to pretreatment and reference forest conditions. The decline

31 was greatest in the mid- and high-elevation hardwood zones of the watershed,

32 where soils are thinnest and have the lowest base saturation and exchangeable

33 Ca pools. Restoration of soil Ca appears to have reduced the allocation of $\mathrm{C}$ to root systems, coincident with observed increases in aboveground biomass and

35 productivity. Therefore, we suggest that relatively higher tree $\mathrm{C}$ allocation to roots in the past contributed to the depressed aboveground productivity

37 observed in northern hardwood forest ecosystems impacted by acid deposition.

38 Keywords: acidification, allocation, leaf area index, mycorrhizae, production 


\section{Introduction}

Soils and surface waters in industrialized regions have been acidified as a

42 result of high atmospheric deposition of strong acids derived primarily from the

43 burning of fossil fuels (Likens et al. 1996; Schindler 1988). The negative effects of

44 acid deposition on forest growth and health have been suggested by both field

45 surveys (Schulze 1989) and controlled experiments (Eagar and Adams 1992).

46 However, forests are exposed to many stresses and isolating the mechanisms by

47 which acid deposition contributes to forest decline has been challenging (Manion 1991). Acid deposition can deplete available pools of soil base cations, especially

49 calcium and magnesium, leading to disruption of physiological processes in sensitive tree species (DeHayes et al. 1999). Although air quality regulations in

51 North America and Europe have reduced acid deposition since the late $20^{\text {th }}$

52 century, severe depletion of base cations has caused persistent effects on

53 sensitive forests (Long et al. 2009; Battles et al. 2014) and soil base cation pools

54 continue to decline (Warby et al. 2009). Moreover, high acid deposition

55 continues to acidify soils in rapidly industrializing regions, like eastern Asia

56 (Dentener et al. 2006, Yang et al. 2015), with likely consequences for forest

57 ecosystems. Hence, a better understanding of forest responses to soil base cation 
58 depletion is essential to characterize and quantify the effects of and recovery

59 from elevated acid deposition.

At the Hubbard Brook Experimental Forest (HBEF) in the northeastern

61 United States, long-term monitoring of forests, soils and surface waters has

62 provided a quantitative basis for evaluating ecosystem responses to acid

63 deposition; in particular, the magnitude of available soil calcium (Ca) depletion

64 during the $20^{\text {th }}$ century has been estimated (Likens et al. 1998). On this basis, a

65 long-term experiment was initiated to replace the lost Ca through an

66

67

72 decreases in solution aluminum (Cho et al. 2010, Nezat et al. 2010, Johnson et al.

73 2014, Shao et al. 2015); improved health of acid-sensitive tree species, including

74 red spruce (Hawley et al. 2006) and sugar maple (Juice et al. 2006); and an overall

75 increase in forest biomass and aboveground productivity, relative to untreated,

76 reference watersheds (Battles et al. 2014). Moreover, in complementary, plot- 
77 level studies at the HBEF the mechanism of Ca effects on sugar maple health and

78

79

80

81

82

83

84

85

86

87

88

89

90

91

92

93

94

95

growth have been demonstrated (Huggett et al. 2007; Halman et al. 2013, 2014).

Two key features of forest recovery resulting from amelioration of soil Ca

depletion on WS1 were observed: 1) promotion of wound closure and damage

recovery following a severe ice storm that coincided with the experimental $\mathrm{Ca}$

additions (Huggett et al. 2007, Battles et al. 2014) and 2) increased aboveground

growth associated with improved canopy health, including wood growth and leaf

production (Juice et al. 2006, Battles et al. 2014). The latter effects raise the

question of the mechanisms whereby low Ca supply in soils depleted by acid

deposition might constrain leaf and wood production. One possible mechanism is

an increase in carbon allocation to root systems seeking access to limited soil

nutrients (Haynes and Gower 1995). The objective of the present study was to

quantify fine root biomass in treated and untreated reference forests. We

hypothesized that historical soil Ca depletion increased fine root biomass as well

as the fine root: leaf biomass ratio. Thus, we predicted that these values would be

greater in the untreated, reference forest than in the Ca-treated forest. If true,

this may help explain the observed increase in aboveground production on the

treated watershed (Battles et al. 2014). We expected differences in root biomass

to be greatest in the mid- and high-elevation hardwood zones of the watersheds, 
96 where the soils have been most severely depleted of base cations (Johnson et al.

97 2000), and where the aboveground growth response to treatment was most

98 pronounced (Battles et al. 2014). Finally, we expected the depth distribution of

fine roots to extend deeper in the soils of the reference than the treated forest as

100 the trees explored deeper soil layers for the limited supply of Ca.

\section{Methods}

Site Description. The HBEF is located in north-central New Hampshire, USA (43은

$56^{\prime} \mathrm{N}, 71045^{\prime} \mathrm{W}$ ), and has been the site of numerous forest research studies.

Detailed description of the site is available elsewhere (Likens 2013). Briefly, the

climate is humid-continental with short, cool summers and long, cold winters.

Soils are predominantly well-drained Spodosols (Haplorthods) and Inceptisols

$\mathrm{HBEF}$ is mostly second-growth forest developed following logging in the late $19^{\text {th }}$

111 and early $20^{\text {th }}$ century. Some areas were also affected by the 1938 hurricane and

112 subsequent salvage logging, and by an intense ice storm in 1998 (Rhoads et al. 
114 most of the damage was restricted to the mid-to-upper elevations of the

115 watersheds and by 2001, leaf area had recovered in affected areas (Green et al.

116 2014; Battles et al. 2014). The Ca amendment was conducted in experimental

117 watershed 1 (WS1, 11.8 ha in size, 488 to $747 \mathrm{~m}$ in elevation) on the south-facing

118 slope of the HBEF. A complete inventory of trees in each of three elevation zones

119 in the northern hardwood forest was conducted in 2001 (Table 1) and repeated in

120 2011. The nearby forest to the west of WS6 served as a reference for

121 measurement of root biomass and leaf area index (LAI), and a complete tree

122 inventory also was conducted on adjacent untreated reference WS6 in 2002 and 1232012.

124 Experimental Ca amendment. In October 1999 (soon after leaf fall), $40.8 \mathrm{Mg}$ of

125 powdered and pelletized wollastonite $\left(\mathrm{CaSiO}_{3}\right)$ was evenly distributed by

126 helicopter to WS1 (Peters et al. 2004). The wollastonite application resulted in a

127 Ca addition of approximately $1,028 \mathrm{~kg} \mathrm{Ca} \mathrm{ha}^{-1}$. This delivery rate was chosen to

128 roughly double soil base saturation to estimated pre-industrial values (Peters et

129 al. 2004), and consequently to increase soil pH and decrease Ca to aluminum (Al)

130 ratios in soil solutions. By summer 2000 the treatment had significantly

131 increased $\mathrm{pH}$ in the Oie horizon (Cho et al. 2010), and the $\mathrm{pH}$ differences have

132 persisted (Table 2; Johnson et al. 2014). The wollastonite addition also 
133 significantly increased the exchangeable $\mathrm{Ca}$ and decreased exchangeable $\mathrm{Al}$ in

134 soils across the elevation gradient in WS1. With time since the addition, the

135 impacts of the treatment (e.g., increasing $\mathrm{pH}$ and exchangeable and solution $\mathrm{Ca}$,

136 decreasing exchangeable and solution $\mathrm{Al}$ ) were detected through the soil profile

137 (Cho et al. 2012, Johnson et al. 2014).

138

139

140

141

142

143

144

145

146

147

148

149

150

151

Field sampling and laboratory processing. Prior to Ca treatment three large sampling plots ( 0.5 to 1 ha rectangular plots) were established across the elevation gradient in WS1 and in nearby forest west of WS6, the biogeochemical reference watershed for the HBEF. The plots in each forest were located in the northern hardwood forest zone at low (488-565 m), mid (565-660 m) and high (660-770 m) elevation. In each plot a network of twelve sampling locations was chosen randomly and at each location a litterfall trap $\left(0.1 \mathrm{~m}^{2}\right)$ was positioned about $1.5 \mathrm{~m}$ above the ground. Leaf litterfall was collected from each trap beginning in 1992 for reference plots and in 1998 for WS1. Hardwood leaf litter was sorted by species for each litter trap each year, providing the amount of leaves per $0.1 \mathrm{~m}^{2}$. Area per leaf of each species was measured on both reference and treated sites in four years in order to convert leaf number to leaf area index $\left(\mathrm{LAl}, \mathrm{m}^{2} \cdot \mathrm{m}^{-2}\right)$ for the northern hardwood forest. Because an ice storm greatly reduced leaf litterfall in parts of both treatment and reference watersheds 
152 between 1999-2000 (Rhoads et al. 2002), we used litterfall values for 2001 to

153

154

155

156

157

158

159

160

161

162

163

164

165

166

167

168

169

170 represent pretreatment conditions.

In August 1998 (prior to treatment) soil cores were collected adjacent to

each of the 36 litterfall traps in WS1 and in the reference forest plots. A split PVC

corer of $5 \mathrm{~cm}$ diameter was hammered into the soil to a depth of $20 \mathrm{~cm}$ as

measured from the top of the mineral soil. Locations occupied by boulders and

root crowns were avoided. Soil cores were divided in the field into four layers:

forest floor organic horizon plus $0-5 \mathrm{~cm}$ mineral soil and 5-10, 10-15, and 15-20

$\mathrm{cm}$ mineral soil. Fine roots in this forest are highly concentrated in shallow soil

layers, with $80-90 \%$ of $<1 \mathrm{~mm}$ roots in forest floor plus $0-20 \mathrm{~cm}$ mineral soil (Fahey

et al. 1988, Yanai et al. 2006). The same field procedure was repeated in August

2013 fourteen years after treatment with cores again paired with litterfall traps.

Soil samples were returned to the laboratory and stored frozen until processed

for root biomass. Roots were hand sorted from soil cores into two diameter

classes (<1 mm, 1-2 mm); live roots were distinguished by visual criteria and

retained for dry weight determination. Roots were dried to constant mass at 70

${ }^{\circ} \mathrm{C}$ and weighed to $\pm 0.001 \mathrm{~g}$. The root biomass data were computed on a grams

per $\mathrm{m}^{2}$ basis (forest floor plus $0-20 \mathrm{~cm}$ mineral soil depth) after taking into

account the estimated area of each sampling plot that was occupied by boulders 
171 and root crowns and hence was not sampled by root coring. A line intercept

172 method was applied to determine this fraction (Fahey et al. 2005).

173 Statistical Analysis. To evaluate the effects of the Ca-amendment on fine root

174 biomass, we used a before-after-control-impact study design (Stewart-Oaten et

175 al. 1986). This framework accounts for temporal changes that are unrelated to the

176 treatment and thus any observed differences between watersheds can be

177 attributed to the Ca- amendment. We emphasize the caveat that our

178 experimental treatment is not replicated as a result of the high cost of the whole

179 watershed treatment that was essential to element mass-balance calculations for

180 the overall study (Johnson et al. 2014). Formally, the impact of the treatment can

181 be quantified as the difference in the response between sites (WS1 and west of

182 WS6 reference, see above) observed over time:

Equation 1

$$
\text { Treatment Impact }=\left(\mu_{\mathrm{ca}}-\mu_{\mathrm{cb}}\right)-\left(\mu_{\mathrm{ta}}-\mu_{\mathrm{tb}}\right)
$$

186 where $\mu$ is the mean of the response variable; $c$ represents the reference

187 watershed; a the measurement period after treatments; $b$ the period before

188 treatments; and $\mathrm{t}$ the treated watershed. A key assumption with this approach is 
190 be constant (Stewart-Oaten et al. 1986). The impact of the treatment on fine root 191 biomass (<1mm; $1-2 \mathrm{~mm}$ ) and the ratio of fine roots to leaf litter biomass was 192 assessed with linear and linear mixed effects models (Pinheiro and Bates 2006). The base model included both time (pre vs post) and treatment (no added 194 Ca vs Ca-amendment) because in the simplest case the time:treatment 195 interaction term serves as the test of the statistical significance of the treatment 196 effect (Smith 2002). We also considered elevation class (low, medium, high 197 elevation sites) as a potential co-variable given the documented patterns in forest 198 composition (Bormann et al. 1970), soil chemistry (Cho et al. 2010) and 199 productivity (Fahey et al. 2005) with elevation (Table 1). Since we sampled fine 200 roots and measured leaf litterfall from the same locations both pre- and post201 treatment, we included models with a random effects term to account for any 202 differences among location. Before fitting the linear models for $<1 \mathrm{~mm}$ and $1-2$ $203 \mathrm{~mm}$ roots, we log-transformed the root biomass to maintain a normal distribution 204 of the residual errors. To select which models were best supported by the data, 205 we calculated the differences in the Akaike Information Criterion (AIC, Burnham 206 and Anderson 2002). We used Akaike weights and evidence ratios to interpret the 207 results. 
biomass versus soil depth to determine whether significant changes occurred in

210 the depth distribution of fine roots in response to the treatment. Again, pre- and

211 post-treatment estimates were available to support this analysis.

\section{Results}

214 Fine root biomass ( $<1 \mathrm{~mm}$ and $1-2 \mathrm{~mm}$ ) was measured in 1998 (pre-treatment)

215 and 2013 (14-yr post-treatment) in both the reference and the treated watershed

216 (Table 3). In general, fine root biomass was lower in 2013 than in 1998 in WS1

217 (Fig. 1). The best fitting model for the effect of Ca-amendment on $<1 \mathrm{~mm}$ fine root

218 biomass included elevation without a random effects term (Table 4). The support

219 for this model was 37 times greater than the next best model. Fine root biomass

220 was greatly reduced in the treated watershed compared to the reference

221 watershed $(p<0.001$, Time:Treatment term in ANOVA; Table 4$)$. The response of

222 fine root biomass also varied significantly with elevation, with the greatest

223 response at higher elevation zones (Fig. 1).

Fine root cores were paired with leaf litterfall collectors in the hardwood

225 forest, and we calculated the mass ratio of $<1 \mathrm{~mm}$ fine root biomass to leaf

226 litterfall biomass for each location (Fig. 2). In general, whereas the fine root:leaf 
227 biomass ratio declined between 2001 and 2013 in the treated watershed, it was 228 either constant or increased in the reference forest (Fig. 2). The statistical results 229 (Table 5) were similar to those for fine root biomass. Whereas the top two models 230 (with and without elevation effects) were indistinguishable, in both cases the 231 treatment effect was highly significant $(p<0.0014$; Table 5); however, for the fine 232 root:leaf biomass ratio, differences with elevation were less pronounced than for 233 fine root biomass.

We evaluated possible shifts in the depth distribution of fine roots between years and watersheds by comparing the slope of bivariate linear models of log 236 (fine root biomass) vs. soil depth. High scatter was observed, and the high-

237 elevation hardwood zone was the only elevation stratum in which a consistent 238 response was evident (Fig. 3). In the reference watershed the slope was nearly 239 identical between years, whereas in the treated watershed the slope showed a 240 weak trend $(p=0.14)$ to be greater in 2013 than 1998 , suggesting that fine roots 241 may have been distributed deeper prior to the treatment in WS1. In contrast to the clear effects of treatment on the biomass of $<1 \mathrm{~mm}$ fine 243 roots, no significant effects $(P=0.302)$ were observed for treatment effects on 244 the biomass of 1-2 $\mathrm{mm}$ roots. Although 1-2 mm root biomass seemed to decline 
245 in the high-elevation zone of WS1, it did not decline in the low and mid-elevations

246 (Table 3). These larger roots comprised about one-third as much biomass as the <

$2471 \mathrm{~mm}$ roots and showed relatively higher spatial variation within sites (Table 3).

\section{Discussion}

We replaced the Ca lost as a result of elevated leaching associated with acid

250 deposition in the $20^{\text {th }}$ century in the form of a rapidly-weathering silicate mineral

251 in an experimental watershed (WS1) at the HBEF with the aim of returning soil

252 base status to levels comparable to pre- $20^{\text {th }}$ century conditions (Peters et al.

253 2004, Johnson et al. 2014). Improved forest health (Juice et al. 2006, Hawley et

254 al. 2006) and increased aboveground biomass and productivity (Battles et al.

255 2014) were observed on the treated watershed relative to reference sites (Table

256 6). Our observations in this study support the hypothesis that the aboveground

257 productivity response on WS1 resulted in part from decreased tree allocation to

258 roots: both fine root biomass (Fig. 1) and the fine root:leaf litterfall mass ratio

259 (Fig. 2) declined significantly 14 years after Ca addition. Looking back in time, this

260 result suggests that soil base cation depletion due to acidification probably

261 caused decreased aboveground productivity on these naturally-acidic soils in part

262 by stimulating an increase in belowground allocation to support greater fine root 
263 biomass. Root biomass in forests can fluctuate significantly among years

264 (Makkonen and Helmisaari 2001), and some uncertainty is acknowledged because

265 our measurements were confined to only one post-treatment year. We also

266 emphasize that our large-scale treatment was not replicated in space, and the

267 results should be applied to broader regions with due caution.

Although biomass of small woody roots $(1-2 \mathrm{~mm})$ also tended to decline, at least in the high elevation zone of the treated watershed (Table 3), the response was less consistent, perhaps reflecting in part the much longer lifespan of these

271 high-order roots (Fahey et al. 2012) and a consequently delayed response. This

272 result also implies a likely response in root branching morphology with more low-

273 order (< 1mm; order 1-3) roots per unit high-order (1-2 mm; order 4-5) roots in 274 the treated forest.

276 production in forests indicate variable responses. In tropical forests fine root

277 biomass typically is inversely related to soil Ca availability (Gower 1987, Cavelier

278 1992). Long-term liming of boreal conifer forests has often resulted in reduced

279 fine root biomass and production (Helmisaari and Hallbacken 1999, Saarsalmi and 
281 tips (Lehto 1994). In contrast to the present study, liming can elicit tree growth 282 reduction in Picea abies, accompanying reduced root biomass and production on 283 some sites, possibly because of impaired $\mathrm{N}$ nutrition associated with reduced fine 284 root and mycorrhizal growth (Lehto and Malkonen 1994). On WS1, Ca addition 285 initially tightened the $\mathrm{N}$ cycle but did not significantly affect foliar $\mathrm{N}$ of the 286 dominant trees (Groffman et al. 2006); higher soil N availability at HBEF than the 287 Scandinavian boreal sites may contribute to these contrasting results. Notably, 288 arbuscular mycorrhizal colonization of sugar maple can be stimulated by $\mathrm{Ca}$ 289 addition (Coughlan et al. 2000, Juice et al. 2006). Although $\mathrm{Ca}$ is an important plant macronutrient, it has not traditionally been regarded as a growth-limiting nutrient in forests; rather, $\mathrm{Ca}$ is thought to exert its role in tree nutrition primarily by buffering soil $\mathrm{pH}$ and thereby suppressing toxic metal effects (Rengel and Zhang 2003). However, recent studies have implicated Ca deficiency in reduced tree growth and health through 295 effects on photosynthesis, carbohydrate metabolism and cold tolerance 296 (McLaughlin and Wimmer 1999, Schaberg et al. 2006, Halman et al. 2008, 2013). 297 Also, previous reports from the WS1 Ca treatment have indicated that forest 298 recovery from ice storm damage was promoted by improved Ca supply on WS1 299 (Battles et al. 2014), supporting complementary observations from HBEF of 
300 improved wound repair in sugar maple on Ca-amended plots (Huggett et al. 301 2007).

Restoration of soil Ca on WS1 resulted in significant increases in foliar and

303 fine root Ca concentrations in all the dominant tree species relative to untreated reference sites (Green et al. 2013; T. Fahey, unpublished data), suggesting that

305 historical soil Ca depletion has impaired tree Ca acquisition on the experimental watersheds at the HBEF. A significant increase in leaf area index (LAI) in the

307 hardwood forest zones was observed on WS1 (Green et al. 2013, Battles et al. 2014), and perhaps reduced Ca availability constrained leaf development on the

309 Ca-depleted reference sites. The increase in LAl coincided with higher aboveground production during year 6 to 11 after treatments, which was attributed to significantly greater leaf and wood production (Battles et al. 2014). accompanied by significantly lower fine root biomass, suggesting that reduced $C$

314 allocation belowground may have contributed to the increased tree growth.

315 However, fine root biomass is an incomplete indicator of belowground C

316 allocation because differences in fine root turnover and metabolism and

317 rhizosphere $\mathrm{C}$ flux also could contribute to variations in allocation. Park et al. 
318 (2008) observed that fine root turnover increased with soil Ca availability across a 319 gradient of New England forests. If restoration of Ca on WS1 resulted in 320 increased root turnover, this would tend to counteract the proposed reduction in 321 C allocation. Notably, the Ca gradient studied by Park et al. (2008) encompassed 322 over a 20 -fold range of soil Ca availability as compared with the roughly 2 -fold 323 increase associated with the present experiment (Table 2; Johnson et al. 2014).

324 Nevertheless, further studies of root growth and turnover in the WS1 experiment 325 are needed to confirm the mechanism of aboveground growth response 326 suggested by our data. Reduced allocation of $\mathrm{C}$ to roots is likely to result in long-term effects on soil C pools. Johnson et al. (2014) reported significant decreases in the pools of 329 organic matter and C in the Oa horizon on WS1 starting seven years posttreatment. By 2010, the $\mathrm{C}$ pool in the Oa horizon had declined by $1130 \mathrm{~g} \mathrm{~m}^{-2}$. This

331 value is large compared to the decrease in fine root biomass observed in this 332 study ( 100-150 $\mathrm{g} \mathrm{m}^{-2}$; Fig. 1); however, together with increased litter decay 333 (Lovett et al. 2016), lower belowground C allocation over several years could 334 contribute to the observed decrease in soil $\mathrm{C}$ after the Ca treatment. 
observed in the mid- and upper-elevation hardwood forest zones on WS1 (Fig. 1).

This result matches observations of increased tree biomass, growth and LAI,

which were also most pronounced at higher elevations, especially for sugar maple

(Table 6). Soils in the high-elevation hardwood zones on the experimental

elevations (Johnson et al. 2000), and soils and soil solutions also exhibited a

greater relative response to the Ca addition in this zone (Cho et al. 2010, 2012,

WS1 have increased markedly from near detection limits before 2010, reaching

347 the exact mechanism remains unknown, it seems likely that increased nitrate depth distribution of fine roots between pre-treatment and 14-yr post-treatment;

351 fine roots appeared to be distributed more deeply in the soil before treatment

352 (Fig. 3). In contrast, Schulze (1989) suggested that shallow rooting of declining 
surface horizons associated with recycling of base cations in plant litter.

Moreover, Bullen and Bailey (2005) showed that during the $20^{\text {th }}$ century

acidification of soils in a New Hampshire conifer forest, root Ca acquisition moved progressively from deeper to shallower horizons. Notably, the Ca treatment on WS1 resulted in only marginally increased base saturation and Ca availability in mineral soil as of 2010 (Johnson et al. 2014); thus, possible increase in fine root deployment in surface soils in the high elevation hardwood zone may reflect relatively high Ca supply associated with leaf litter recycling (Fahey and Blum 2011) relative to deeper soil layers. Previous research at the HBEF (Blum et al. 2002 ) indicated that mycorrhizae contributed significantly to weathering of $\mathrm{Ca}$ from apatite in mineral soil of these base-poor watersheds, perhaps contributing to deeper rooting prior to the treatment.

The large-scale Ca addition to WS1 at the HBEF was explicitly designed to measure long-term responses of forest ecosystem dynamics to the amelioration of soil base cation depletion resulting from human activity in the $20^{\text {th }}$ century. Our results suggest that one key effect of soil Ca depletion on naturally acid soils was increased fine root biomass in northern hardwood forests. Widespread observations of improved health and growth in northern hardwood forests in response to base cation additions (Wilmot et al. 1996, Moore et al. 2012, Long et 
373 al. 2009) may be partly explained by responses in tree $C$ allocation belowground.

374 Further study of fine root dynamics in Ca-amended forest soils is needed to clarify

375 the mechanisms of forest ecosystem responses to base cation depletion and its 376 mitigation.

\section{Acknowledgements}

379 undergraduate assistants for their contribution to this research. Funding for the

380 research was provided by National Science Foundation through the LTER Program

381 (Grant \# 1114804) and the Division of Environmental Biology (Grant \# 9726837).

382 This is a contribution from the Hubbard Brook Ecosystem Study. The Hubbard

383 Brook Experimental Forest is administered by the USDA, Forest Service Northern

384 Research Station, Newtown Square, PA. 
387 Battles, J. Fahey, T.J., Driscoll, C.T., Blum, J.D., and Johnson, C.E. 2014. Restoring 388 soil calcium reverses forest decline. Environ. Sci. Technol. Lett. 1(1): 15-19, DOI: 389 10.1021/ez40003.

390 Blum, J.D., Klaue, A., Nezat, C.A., Driscoll, C.T., Johnson, C.E., Siccama, T.G., and 391 Likens, G.E. 2002. Mycorrhizal weathering of apatite as an important calcium 392 source in base-poor forest ecosystems. Nature 417(6890):729-731.

393 Bormann, F.H., Siccama, T.G., Likens, G.E., and Whittaker, R.H. 1970. The 394 Hubbard Brook ecosystem study: composition and dynamics of the tree 395 stratum. Ecol. Monogr. 40:373-388.

396 Bullen, T.D., and Bailey, S.W. 2005. Identifying calcium sources at an acid 397 deposition-impacted spruce forest: a strontium isotope, alkaline earth element 398 multi-tracer approach. Biogeochemistry 74(1): 63-99.

399 Burnham, K.P., and Anderson, D.R. 2002. Model selection and multimodel 400 inference: a practical information-theoretic approach. Springer Science and 401 Business Media. XXVI, 488, doi: 10.1007/b97636.

402 Cavelier, J. 1992. Fine-root biomass and soil properties in a semideciduous and a 403 lower montane rain forest in Panama. Plant Soil 142(2):187-201.

404 Cho, Y., Driscoll, C.T., Johnson, C.E., and Siccama, T.G. 2010. Chemical changes in 405 soil and soil solution after calcium silicate addition to a northern hardwood forest. 406 Biogeochemistry 100(1-3):3-20.

407 Cho, Y., Driscoll, C.T., Johnson, C.E., Blum, J.D., and Fahey, T.J. 2012. Watershed408 level responses to calcium silicate treatment in a northern hardwood 409 forest. Ecosystems 15(3):416-434.

410 Coughlan A.P., Dalpé, Y., Lapoint, L., and Piché, Y. 2000 Soil pH-induced changes in 411 root colonization, diversity, and reproduction of symbiotic arbuscular mycorrhizal 412 fungi from healthy and declining maple forests. Can J Forest Res 30: 1543-1554. 413 doi: 10.1139/cjfr-30-10-1543 
414 DeHayes, D.H., Schaberg, P.G., Hawley, G.J., and Strimbeck, G.R. 1999. Acid rain 415 impacts on calcium nutrition and forest health alteration of membrane-associated 416 calcium leads to membrane destabilization and foliar injury in red spruce.

417 BioScience 49(10):789-800.

418 Dentener, F., Drevet, J., Lamarque, J.F., Bey, I., Eickhout, B., Fiore, A.M., 419 Hauglustaine, D., Horowitz, L.W., Krol, M., Kulshrestha, U.C., Lawrence, M., Galy420 Lacaux, C., Rast, S., Shindell, D., Stevenson, D., Van Noije, T., Atherton, C., Bell, N., 421 Bergman, D., Butler, T., Cofala, J., Collins, B., Doherty, R., Ellingsen, K., Galloway, 422 J., Gauss, M., Montanaro, V., Mueller, J.F., Pitari, G., Rodriguez, J., Sanderson, M., 423 Solmon, F., Strahan, S., Schultz, M., Sudo, K., Szopa, S., Wild, O. 2006. Nitrogen 424 and sulfur deposition on regional and global scales: A multimodel evaluation. 425 Global Biogeochem. Cycles 20, GB4003, doi:10.1029/2005GB002672.

426 Driscoll, C.T., Lawrence, G.B., Bulger, A.J., Butler, T.J., Cronan, C.S., Eagar, C., 427 Lambert, K.F., Likens, G.E., Stoddard J.L., and Weathers, K.C. 2001. Acidic 428 Deposition in the Northeastern United States: Sources and Inputs, Ecosystem 429 Effects, and Management Strategies. Bioscience 51:180-198.

430 Eagar, C., and Adams, M.B. 1992. Ecology and decline of red spruce in the eastern 431 United States. Vol. 96, Ecological Studies: Analysis and Synthesis. Springer-Verlag, 432 New York, Inc.

433 Fahey, T.J., Hughes, J.W., Pu, M. and Arthur, M.A. 1988. Root decomposition and 434 nutrient flux following whole-tree harvest of northern hardwood forest. Forest Science 34:744-768.Fahey, T.J., and Blum, J.D. 2011. Litter layers (Oie) as a 436 calcium source of sugar maple seedlings in a northern hardwood forest. Can. J. 437 For. Res. 41(4):898-901.

438 Fahey, T.J., Siccama, T.G., Driscoll, C.T., Likens, G.E., Campbell, J., Johnson, C.E., 439 Aber, J.D., Cole, J.J., Fisk, M.C., Groffman, S.P., Hamburg, S.P., Holmes, R.T., 440 Schwarz, P.A. and Yanai, R.D. 2005. The biogeochemistry of carbon at Hubbard 441 Brook. Biogeochemistry 75(1): 109-176. 
442 Fahey, T.J., Tierney, G.L., Fitzhugh, R.D., Wilson, G.F., and Siccama, T. G. 2005b.

443 Soil respiration and soil carbon balance in a northern hardwood forest ecosystem.

444 Can. J. For. Res. 35(2), 244-253.

445 Fahey, T.J., Jacobs, K.R., and Sherman, R.E. 2012. Fine root turnover in sugar

446 maple estimated by ${ }^{13} \mathrm{C}$ isotope dilution. Can. J. For. Res. 42(10): 1792-1795, DOI:

$447 \quad 10.1139 / \times 2012-128$.

448 Green, M.B., Bailey, A.S., Bailey, S.W., Battles, J.J., Campbell, J.L., Driscoll, C.T., 449 and Schaberg, P.G. (2013). Decreased water flowing from a forest amended with 450 calcium silicate. Proc. Natl. Acad. Sci. 110(15): 5999-6003.

451 Gower, S.T. 1987. Relations between mineral nutrient availability and fine root 452 biomass in two Costa Rican tropical wet forest: a hypothesis. Biotropica 19: 171$453 \quad 175$.

454 Groffman, P.M., Fisk, M.C., Driscoll, C.T., Likens, G.E., Fahey, T.J., Eagar, C. and 455 Pardo, L.H. 2006. Calcium Additions and Microbial Nitrogen Cycle Processes in a 456 Northern Hardwood Forest. Ecosystems 9:1289-1305.

457 Halman, J.M., Schaberg, P.G., Hawley, G.J., Hansen, C.F., and Fahey, T.J. 2014. 458 Differential impacts of calcium and aluminum treatments on sugar maple and 459 American beech growth dynamics. Can. J. For. Res. 45(1):52-59.

460 Halman, J.M., Schaberg, P.G., Hawley, G.J., and Eagar, C. 2008. Calcium addition at 461 the Hubbard Brook Experimental Forest increases sugar storage, antioxidant 462 activity and cold tolerance in native red spruce (Picea rubens). Tree Physiol. 28(6): $463 \quad 855-862$.

464 Halman, J.M., Schaberg, P.G., Hawley, G.J., Pardo, L.H., and Fahey, T.J. 2013. 465 Calcium and aluminum impacts on sugar maple physiology in a northern 466 hardwood forest. Tree Physiol. 33(11): 1242-1251.

467 Hawley, G.J., Schaberg, P.G., Eagar, C., and Borer, C.H. 2006. Calcium addition at 468 the Hubbard Brook Experimental Forest reduced winter injury to red spruce in a 469 high-injury year. Can. J. For. Res. 36(10): 2544-2549. 
470 Haynes, B.E., and Gower, S.T. 1995. Belowground carbon allocation in unfertilized 471 and fertilized red pine plantations in northern Wisconsin. Tree Physiol. 15(5): 317472325.

473 Helmisaari, H-S., and Hallbäcken, L. 1999. Fine-root biomass and necromass in 474 limed and fertilized Norway spruce (Picea abies (L.) Karst.) stands. For. Ecol. 475 Manage. 119:99-110.

476 Huggett, B.A., Schaberg, P.G., Hawley, G.J., and Eagar, C. 2007. Long-term calcium 477 addition increases growth release, wound closure, and health of sugar maple 478 (Acer saccharum) trees at the Hubbard Brook Experimental Forest. Can. J. For. 479 Res. 37(9):1692-1700.

480 Johnson, C.E., Driscoll, C.T., Blum, J.D., Fahey, T.J., and Battles, J.J. 2014. Soil 481 chemical dynamics after calcium silicate addition to a northern hardwood forest. 482 Soil Sci. Soc. Am. J. 78:1458-1468. doi:10.2136/sssaj2014.03.0114.

483 Johnson, C.E., Driscoll, C.T., Siccama, T.G., and Likens, G.E. 2000. Element fluxes 484 and landscape position in a northern hardwood forest watershed ecosystem. 485 Ecosystems 3(2):159-184.

486 Juice, S.M., Fahey, T.J., Siccama, T.G., Driscoll, C.T., Denny, E.G., Eagar, C., and 487 Richardson, A.D. 2006. Response of sugar maple to calcium addition to northern 488 hardwood forest. Ecology 87(5): 1267-1280.

489 Lehto, T. 1994. Effects of soil pH and calcium on mycorrhizas of Picea abies. Plant 490 Soil 163:69-75.

491 Lehto, T. and Malkonen, E. 1994. Effects of liming and boron fertilization on 492 boron uptake of Picea abies. Plant Soil 163:55-64.

493 Likens, G.E. 2013. Biogeochemistry of a Forested Ecosystem. Springer Science + 494 Business Media, New York. DOI: 10.1007/978-1-4614-7810-2_1.

495 Likens, G.E., Driscoll, C.T., and Buso, D.C. 1996. Long-term effects of acid rain: 496 response and recovery of a forest ecosystem. Science 272(5259):244-245. 
497 Likens, G.E., Driscoll, C.T., Buso, D.C., Siccama, T.G., Johnson, C.E., Lovett, G.M., 498 and Bailey, S.W. 1998. The biogeochemistry of calcium at Hubbard Brook. 499 Biogeochemistry 41(2):89-173.

500 Long, R.P., Horsley, S.B., Hallett, R.A., and Bailey, S.W. 2009. Sugar maple growth 501 in relation to nutrition and stress in the northeastern United States. Ecol. Appl. 502 19(6):1454-1466.

503 Lovett, G.M., Arthur, M.A., and Crowley, K.F. 2015. Effects of calcium on the rate 504 and extent of litter decomposition in a northern hardwood forest. Ecosystems 505 DOI 10.1007/s10021-015-9919-0

506 Makkonen, K., and Helmisaari, H-S. 2001. Fine root biomass and production in 507 Scots pine stands in relation to stand age. Tree Physiol 21:193-198.

508 Manion, P.D., and Lachance, D. 1992. Forest decline concepts. American 509 Phytopathological Society (APS), St. Paul, MN.

510 McLaughlin, S.B., and Wimmer, R. 1999. Tansley review no. 104. Calcium 511 physiology and terrestrial ecosystem processes. New Phytol. 142(3):373-417.

512 Moore, J-D., Ouimet, R., and Duchesne, L. 2012. Soil and sugar maple response 51315 years after dolomitic lime application. For. Ecol. Manage. 281:130-139.

514 Nezat, C.A., Blum, J.D., and Driscoll, C.T. 2010. Patterns of Ca/Sr and 87Sr/86Sr 515 variation before and after a whole watershed $\mathrm{CaSiO} 3$ addition at the Hubbard 516 Brook Experimental Forest, USA. Geochimica et Cosmochimica Acta 74:3129517 3142. doi:10.1016/j.gca.2010.03.013.

518 Park, B.B., Yanai, R.D., Fahey, T.J., Bailey, S.W., Siccama, T.G., Shanley, J.B., and 519 Cleavitt, N.L. 2008. Fine root dynamics and forest production across a calcium 520 gradient in northern hardwood and conifer ecosystems. Ecosystems 11(2):325521341.

522 Peters, S.C., Blum, J.D., Driscoll, C.T., and Likens, G.E. 2004. Dissolution of 523 wollastonite during the experimental manipulation of Hubbard Brook watershed 524 1. Biogeochemistry 67:309-329. doi:10.1023/B:BIOG.0000015787.44175.3f. 
525 Pinheiro, J., and Bates, D. 2006. Mixed-effects models in S and S-PLUS. Springer 526 Science \& Business Media.

527 Rengel, Z., and Zhang, W. H. 2003. Role of dynamics of intracellular calcium in 528 aluminium-toxicity syndrome. New Phytol. 159(2): 295-314.

529 Rhoads, A.G., Hamburg, S.P., Fahey, T.J., Siccama, T.G., Hane, E.N., Battles, J., and 530 Wilson, G. 2002. Effects of an intense ice storm on the structure of a northern 531 hardwood forest. Can. J. For. Res. 32(10):1763-1775.

532 Saarsalmi, A. and Malkonen, E. 2001. Forest Fertilization Research in Finland: A 533 Literature Review. Scand. J. Forest Res. 16:514-535.

534 Schaberg, P.G., Tilley, J.W., Hawley, G.J., DeHayes, D.H., \& Bailey, S.W. 2006. 535 Associations of calcium and aluminum with the growth and health of sugar maple 536 trees in Vermont. For. Ecol. Manage. 223(1):159-169.

537 Schindler, D.W. 1988. Effects of acid rain on freshwater ecosystems. Science 538 (Washington), 239(4836): 149-157.

539 Schulze, E.D. 1989. Air pollution and forest decline in a spruce (Picea abies) forest. 540 Science 244(4906):776-783.

541 Shao, S., Driscoll, C.T., Johnson, C.E., Fahey, T.J., Battles, J.J., Blum, J.D., 2016.

542 Long-term responses in soil solution and streamwater chemistry at Hubbard

543 Brook after experimental addition of wollastonite. Environ Chem DOI:

544 10.1071/EN15113.

545 Smith, E.P. 2002. BACl design. In The Encyclopedia of Environmetrics. Edited by 546 A.h. El-Shaarawi and W.W. Piegorsch. John Wiley and Sons. Chichester. Pages $547 \quad 141-148$.

548 Stewart-Oaten, A., Murdoch, W.W., \& Parker, K.R. 1986. Environmental impact 549 assessment:" Pseudoreplication" in time? Ecology 67(4): 929-940.

550 Warby, R.A.F., Johnson, C.E., and Driscoll, C.T. 2009. Continuing acidification of 551 organic soils across the northeastern USA: 1984-2001. Soil Sci. Soc. Am. J. 73:274552 284. doi:10.2136/sssaj2007.0016. 
553 Wilmot, T.R., Ellsworth, D.S. and Tyree, M.T. 1996. Base cation fertilization and 554 liming effects on nutrition and growth of Vermont sugar maple stands. For. Ecol. 555 Manage. 84:123-134.

556 Yanai, R.D., Park, B.B., and Hamburg, S.P. 2006. The vertical and horizontal 557 distribution of roots in northern hardwood stands of varying age. Can. J. For. Res. 558 36: 450-459

559 Yang, Y., Li, P., He, H., Zhao, X., Datta, A., Ma, W., Zhang, Y., Liu, X., Han. W., 560 Wilson, M.C., and Fang, J. 2015. Long-term changes in soil pH across major forest 561 ecosystems in China. Geophys. Res. Lett. 42:933-940. doi:

562 10.1002/2014GL062575. 
564 Table 1. Forest composition and structure in Watershed 1 in 2001 . All trees $\geq 2 \mathrm{~cm}$ included.

565 Only areas of watershed defined as hardwood forest included. Standard error (se) is the

566 sampling error for the $25 \times 25 \mathrm{~m}$ plots included in each elevation zone (Low $=488-565 \mathrm{~m}$

567 elevation; Mid = 565-660 m; High = 660-747 m).

568

\begin{tabular}{|c|c|c|c|c|c|c|}
\hline & \multicolumn{2}{|c|}{ Low $(n=54)$} & \multicolumn{2}{|c|}{ Mid $(n=47)$} & \multicolumn{2}{|c|}{ High $(n=26)$} \\
\hline & mean & se & mean & se & mean & se \\
\hline Density $\left(\#\right.$ ha $^{-1}$ ) & 2,031 & 95 & 2,147 & 99 & 2,852 & 199 \\
\hline Basal area $\left(\mathrm{m}^{2} \mathrm{ha}^{-1}\right)$ & 31.3 & 0.9 & 28.4 & 0.8 & 26.3 & 0.8 \\
\hline Aboveground biomass ( $\mathrm{Mg} \mathrm{ha}^{-1}$ ) & 281.0 & 9.5 & 203.4 & 8.4 & 115.3 & 5.3 \\
\hline \multicolumn{7}{|l|}{ (\% basal area) } \\
\hline American beech & \multicolumn{2}{|c|}{12} & \multicolumn{2}{|l|}{25} & \multicolumn{2}{|c|}{46} \\
\hline Sugar maple & \multicolumn{2}{|c|}{43} & \multicolumn{2}{|l|}{45} & \multicolumn{2}{|c|}{23} \\
\hline Yellow birch & \multicolumn{2}{|c|}{23} & \multicolumn{2}{|l|}{27} & \multicolumn{2}{|c|}{10} \\
\hline
\end{tabular}


571 Table 2. Soil pH (in water), base saturation and pools of exchangeable cations at three depths

572 before (1998) and 11 years after (2010) wollastonite (Ca Si $\mathrm{O}_{3}$ ) treatment of Watershed 1 at the

573 Hubbard Brook Experimental Forest, New Hampshire. "Oie" refers to the combined Oi and Oe

574 soil horizons. Adapted from Johnson et al. (2014).

575

\begin{tabular}{lccc}
\hline Soil property & Depth & $\mathbf{1 9 9 8}$ & $\mathbf{2 0 1 0}$ \\
\hline $\mathrm{pH}$ in water & Oie & 3.88 & 4.71 \\
& Oa & 3.82 & 4.42 \\
& $0-10$ & 3.96 & 4.16 \\
& & & \\
Base saturation & Oie & 49 & 83 \\
(percent) & Oa & 33 & 61 \\
& $0-10$ & 12 & 19 \\
& & & 9.8 \\
Exchangeable Ca $_{\left(\mathrm{kmol}_{\mathrm{c}} \text { ha }^{-1} \text { ) }\right.}$ & Oie & 2.1 & $4.8 \mathrm{~ns}$ \\
& Oa & 4.4 & $3.7 \mathrm{~ns}$ \\
& $0-10$ & 3.2 & $0.51 \mathrm{~ns}$ \\
Exchangeable Al $^{-1}$ ) & Oie & 0.50 & 3.4 \\
(kmol $_{\mathrm{c}}$ ha $^{-10}$ & Oa & 9.6 & 22.2 \\
\hline
\end{tabular}

576

577 ns - no statistically significant difference between 1998 and 2010. 
578 Table 3. Fine root biomass (A. $<1 \mathrm{~mm}$ and B. $1-2 \mathrm{~mm}$ ) in three elevation zones of reference and 579 treated (WS1) watersheds before (1998) and 14 years after treatment (2013) with calcium 580 silicate. Mean $+/$ - standard errors $(n=12)$.

\begin{tabular}{|c|c|c|c|c|c|c|}
\hline \multicolumn{3}{|c|}{ A. $<1 \mathrm{~mm}$ roots } & \multicolumn{4}{|c|}{ Fine root biomass $\left(\mathrm{g} / \mathrm{m}^{2}\right)$} \\
\hline \multirow{17}{*}{$\begin{array}{l}\frac{5}{0} \\
\frac{0}{\pi} \\
\frac{0}{\omega}\end{array}$} & & & \multicolumn{2}{|c|}{1998} & \multicolumn{2}{|c|}{2013} \\
\hline & \multirow{6}{*}{ Low } & & REF & W1 & REF & W1 \\
\hline & & $F F+0-5$ & $289.8 \pm 39.9$ & $230.4 \pm 28.1$ & $257.9 \pm 27.7$ & $196.1 \pm 21.2$ \\
\hline & & $5-10$ & $67.7 \pm 3.8$ & $155.4 \pm 17.3$ & $122.0 \pm 18.9$ & $85.0 \pm 8.7$ \\
\hline & & $10-15$ & $54.8 \pm 9.3$ & $96.2 \pm 11.3$ & $62.0 \pm 9.2$ & $86.5 \pm 11.8$ \\
\hline & & $15-20$ & $45.5 \pm 9.8$ & $91.3 \pm 14.6$ & $45.5 \pm 12.8$ & $69.7 \pm 8.5$ \\
\hline & & Total & $457.6 \pm 58.6$ & $573.3 \pm 32.5$ & $487.5 \pm 48.2$ & $437.3 \pm 29.2$ \\
\hline & \multirow[t]{5}{*}{ Mid } & $F F+0-5$ & $194.8 \pm 24.5$ & $316.4 \pm 42.2$ & $187.7 \pm 25.4$ & $218.5 \pm 22.3$ \\
\hline & & $5-10$ & $74.4 \pm 18.4$ & $131.0 \pm 26.0$ & $86.3 \pm 7.9$ & $93.5 \pm 5.6$ \\
\hline & & $10-15$ & $55.5 \pm 12.6$ & $85.5 \pm 9.2$ & $77.9 \pm 11.0$ & $78.3 \pm 6.0$ \\
\hline & & $15-20$ & $47.0 \pm 7.8$ & $117.1 \pm 48.1$ & $56.0 \pm 11.5$ & $84.0 \pm 10.4$ \\
\hline & & Total & $371.6 \pm 34.4$ & $650.0 \pm 52.2$ & $407.9 \pm 29.3$ & $474.3 \pm 33.5$ \\
\hline & \multirow[t]{5}{*}{ High } & $\mathrm{FF}+0-5$ & $221.9 \pm 50.2$ & $178.3 \pm 27.5$ & $239.3 \pm 35.5$ & $139.5 \pm 18.6$ \\
\hline & & $5-10$ & $106.9 \pm 17.1$ & $90.2 \pm 11.3$ & $80.4 \pm 9.0$ & $52.0 \pm 6.5$ \\
\hline & & $10-15$ & $90.3 \pm 15.9$ & $66.9 \pm 9.6$ & $64.3 \pm 8.8$ & $43.7 \pm 3.6$ \\
\hline & & $15-20$ & $49.7 \pm 13.2$ & $110.9 \pm 33.0$ & $69.9 \pm 11.6$ & $38.6 \pm 4.0$ \\
\hline & & Total & $468.9 \pm 36.9$ & $446.2 \pm 24.0$ & $453.9 \pm 42.1$ & $273.7 \pm 23.8$ \\
\hline
\end{tabular}

581

\begin{tabular}{|c|c|c|c|c|c|c|}
\hline \multicolumn{3}{|c|}{ B. $1-2 \mathrm{~mm}$ roots } & \multicolumn{4}{|c|}{ Fine root biomass $\left(\mathrm{g} / \mathrm{m}^{2}\right)$} \\
\hline & & & \multicolumn{2}{|c|}{1998} & \multicolumn{2}{|c|}{2013} \\
\hline \multirow{16}{*}{ 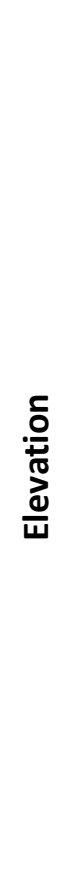 } & \multirow{6}{*}{ Low } & & REF & W1 & REF & W1 \\
\hline & & $F F+0-5$ & $120.4 \pm 18.5$ & $67.9 \pm 17.2$ & $52.09 \pm 10.7$ & $66.0 \pm 17.2$ \\
\hline & & $5-10$ & $31.1 \pm 4.8$ & $31.1 \pm 7.7$ & $27.6 \pm 4.5$ & $27.4 \pm 5.0$ \\
\hline & & $10-15$ & $34.9 \pm 8.8$ & $39.8 \pm 13.4$ & $23.6 \pm 7.5$ & $29.5 \pm 5.6$ \\
\hline & & $15-20$ & $13.3 \pm 6.1$ & $58.6 \pm 18.7$ & $23.1 \pm 14.2$ & $31.7 \pm 8.2$ \\
\hline & & Total & $199.8 \pm 24.0$ & $197.4 \pm 8.4$ & $126.5 \pm 6.9$ & $154.6 \pm 9.1$ \\
\hline & \multirow[t]{5}{*}{ Mid } & $F F+0-5$ & $40.7 \pm 15.9$ & $64.1 \pm 17.3$ & $44.4 \pm 8.3$ & $68.8 \pm 14.6$ \\
\hline & & $5-10$ & $43.2 \pm 7.8$ & $49.6 \pm 14.4$ & $46.6 \pm 9.0$ & $31.6 \pm 6.4$ \\
\hline & & $10-15$ & $34.7 \pm 9.3$ & $55.4 \pm 12.1$ & $40.0 \pm 5.7$ & $27.2 \pm 6.7$ \\
\hline & & $15-20$ & $21.4 \pm 3.7$ & $40.6 \pm 8.6$ & $38.8 \pm 9.9$ & $53.7 \pm 13.4$ \\
\hline & & Total & $140.0 \pm 4.9$ & $209.7 \pm 5.0$ & $169.7 \pm 1.8$ & $181.2 \pm 9.7$ \\
\hline & \multirow[t]{5}{*}{ High } & $F F+0-5$ & $96.2 \pm 25.4$ & $61.8 \pm 18.1$ & $93.5 \pm 17.0$ & $41.5 \pm 4.0$ \\
\hline & & $5-10$ & $16.4 \pm 5.3$ & $28.2 \pm 8.9$ & $33.2 \pm 10.3$ & $13.3 \pm 5.1$ \\
\hline & & $10-15$ & $25.2 \pm 9.3$ & $28.6 \pm 5.9$ & $34.8 \pm 6.1$ & $18.6 \pm 3.9$ \\
\hline & & $15-20$ & $10.7 \pm 8.0$ & $24.1 \pm 5.1$ & $27.6 \pm 6.5$ & $12.0 \pm 3.5$ \\
\hline & & Total & $148.5 \pm 19.9$ & $142.7 \pm 8.8$ & $189.2 \pm 15.5$ & $85.4 \pm 6.9$ \\
\hline
\end{tabular}


584 Table 4. Analysis of variance table for best model of log (fine root biomass, $\mathrm{g} \mathrm{m}^{-2}$ ) comparing 585 reference and treated (WS1) forest at three elevations (low, mid, high) before and 14 years 586 after (Time) treatment with wollastonite (calcium silicate). Treatment effect in $\mathrm{BACl}$ design is 587 indicated by Treatment:Time interaction.

\begin{tabular}{lllll}
\hline Coefficients & Estimate & Std. Error & T value & $\operatorname{Pr}(>|\mathbf{t}|)$ \\
\hline (Intercept) & 5.92821 & 0.07856 & 75.465 & $<2 \mathrm{e}-16$ \\
Treat & -0.17968 & 0.08963 & -2.005 & 0.047061 \\
Time & -0.14034 & 0.09214 & -1.523 & 0.130170 \\
Elevlow & 0.25928 & 0.07872 & 3.294 & 0.001275 \\
Elevmid & 0.16209 & 0.07606 & 2.131 & 0.034968 \\
Treat:Time & 0.42763 & 0.12664 & 3.377 & 0.000968 \\
\end{tabular}

588

589 Note:

590 Residual standard error: 0.3686 on 130 degrees of freedom

591 Multiple R-squared: 0.1605, Adjusted R-squared: 0.1283

592 F-statistic: 4.972 on 5 and 130 DF, p-value: 0.0003364 
593 Table 5. Analysis of variance table for best model of fine root:leaf biomass ratio comparing 594 reference and treated (WS1) forest two years and 14 years after treatment with wollastonite 595 (calcium silicate). Treatment effect in BACl design is indicated by Treatment:Time interaction.

\begin{tabular}{lllll}
\hline Coefficients & Estimate & Std. Error & T value & $\operatorname{Pr}(>|\mathbf{t}|)$ \\
\hline (Intercept) & 0.034213 & 0.002908 & 11.767 & $<2 \mathrm{e}-16$ \\
Time & 0.006659 & 0.004238 & 1.571 & 0.11855 \\
Treat & 0.013630 & 0.004112 & 3.315 & 0.00118 \\
Treat:Time & -0.019575 & 0.005994 & -3.266 & 0.00139 \\
\end{tabular}

596

597 Note:

598 Residual standard error: 0.01745 on 132 degrees of freedom

599 Multiple R-squared: 0.09549, Adjusted R-squared: 0.7493

600 F-statistic: 4.645 on 3 and 132 DF, p-value: 0.004035

601 
602 Table 6. Relative change (\%) in aboveground live biomass by species and elevation zones

603 between the beginning of treatment (2001/2002) and 2011/2012 in reference (WS6) and Ca-

604 treated (WS1) watersheds at the HBEF. Relative change calculated as the difference in biomass

605 between earlier and later inventory. Includes all trees $\geqq 2 \mathrm{~cm}$.

\begin{tabular}{cccc}
\hline & Low & Mid & High \\
\hline WS6 (2002 to 2012) & -20.1 & 16.2 & 10.1 \\
Beech & -2.8 & -12.5 & -13.8 \\
& Sugar maple & -0.7 & 5.7 \\
Yellow birch & -3.2 & -8.4 & 0.7 \\
All & & -6.9 & 15.2 \\
WS1 (2001 to 2011) & -4.2 & -0.1 & 24.3 \\
Beech & 2.1 & 10.1 & -2.8 \\
Sugar maple & -9.7 & -11.3 & 5.1 \\
Yellow birch & 2.7 & 1.3 & \\
\hline
\end{tabular}

606 
607

608

609

610

611

612

613

614

615

616

617

618

619

620

621

622

\section{FIGURE CAPTIONS}

Figure 1. Fine root $(<1 \mathrm{~mm}$ diameter) biomass in a. treated (Watershed 1$)$ and $b$. reference northern hardwood forests in three elevation zones before (1998) and 14 years after treatment (2013) with calcium silicate. Error bars indicate standard errors $(n=12)$.

Figure 2. Ratio of fine root $(<1 \mathrm{~mm})$ mass $\left(\mathrm{g} / \mathrm{m}^{2}\right)$ to leaf litterfall mass $\left(\mathrm{g} / \mathrm{m}^{2}\right)$ in a. treated (Watershed 1) and b. reference northern hardwood forests in three elevation zones two years (2001) and 14 years after treatment (2013) with calcium silicate. Error bars indicate standard errors $(n=$ 12).

Figure 3. Depth distribution of fine roots in a. treated (Watershed 1) and b. reference northern hardwood forests in the high elevation hardwood zone before (1998 dashed) and 14 years after treatment (solid) with calcium silicate. Shaded areas indicate $95 \%$ confidence intervals around the regression lines. 
FIGURE 1

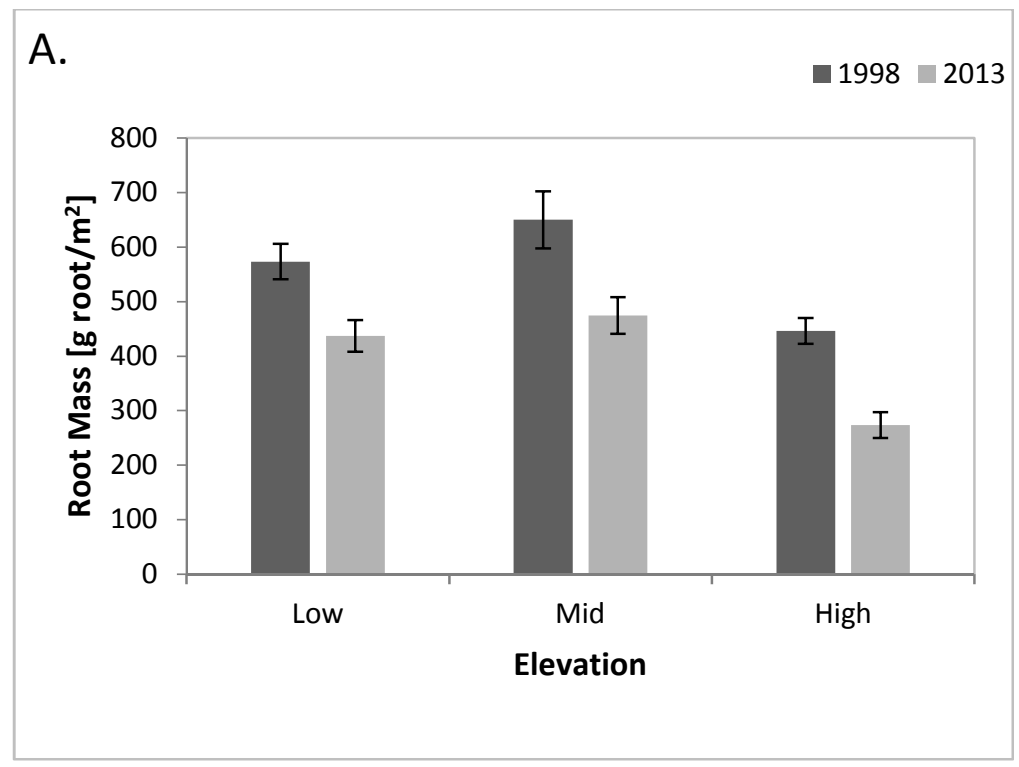

B.

B. $\quad \square 1998 \square 2013$

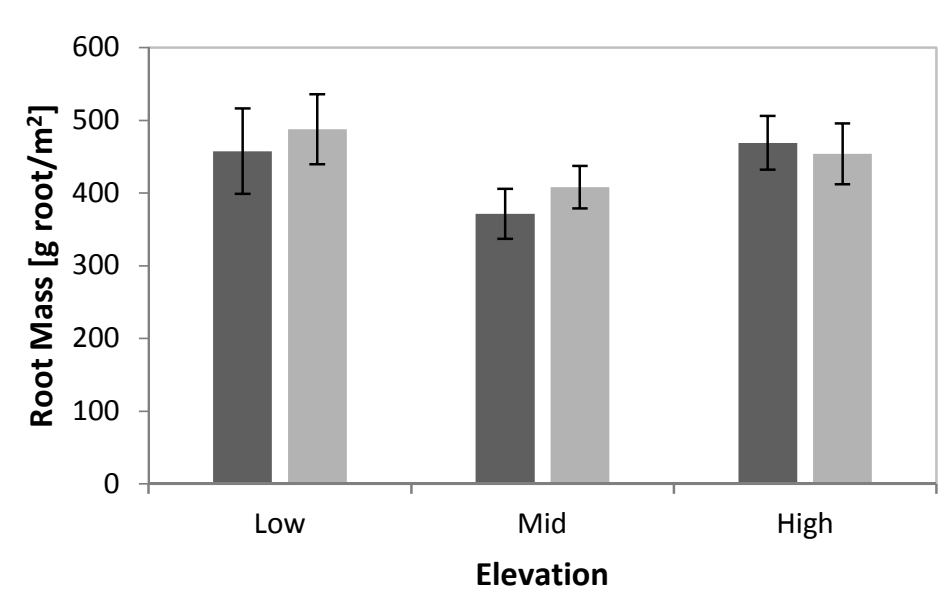


FIGURE 2
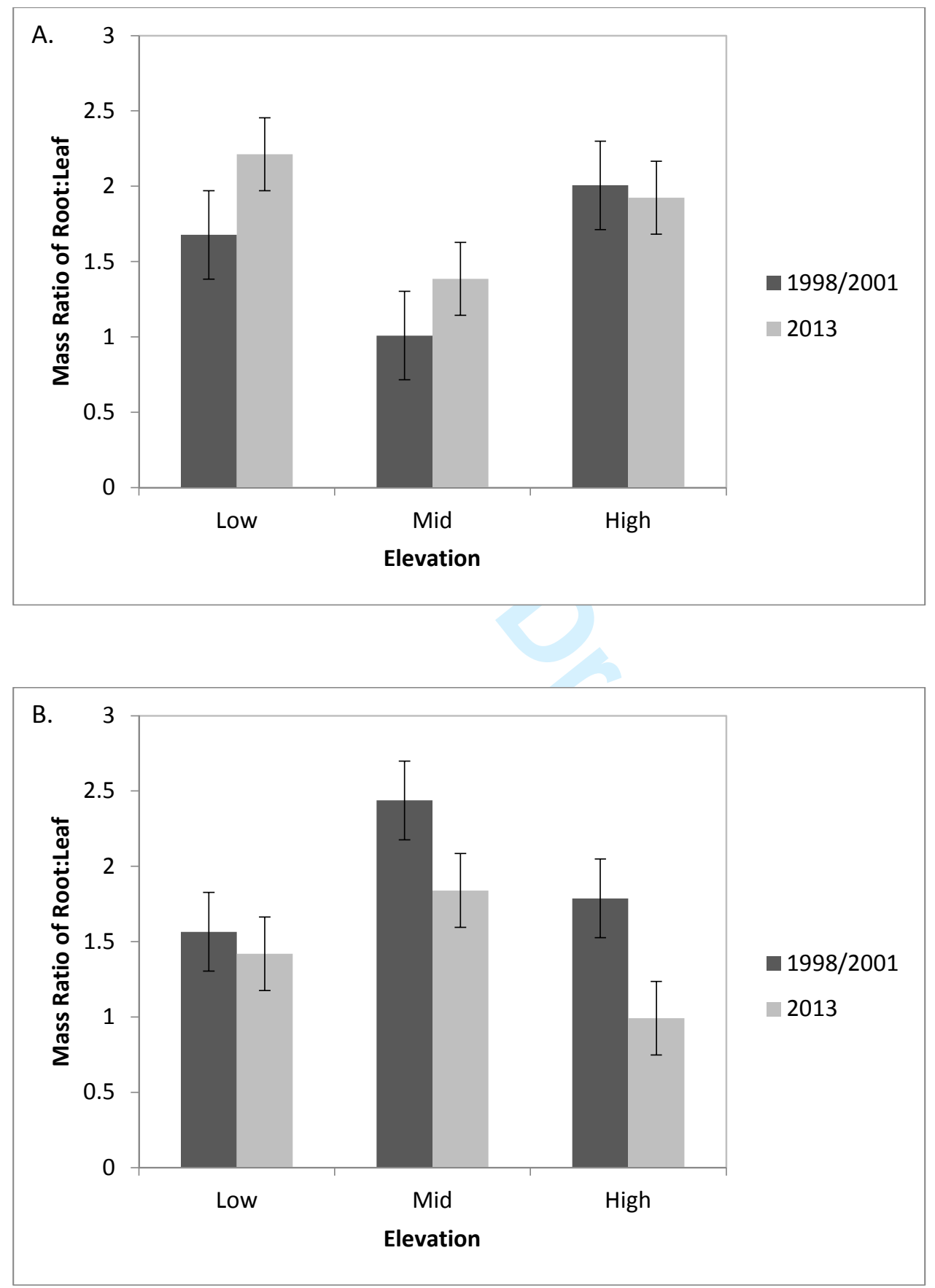
FIGURE 3

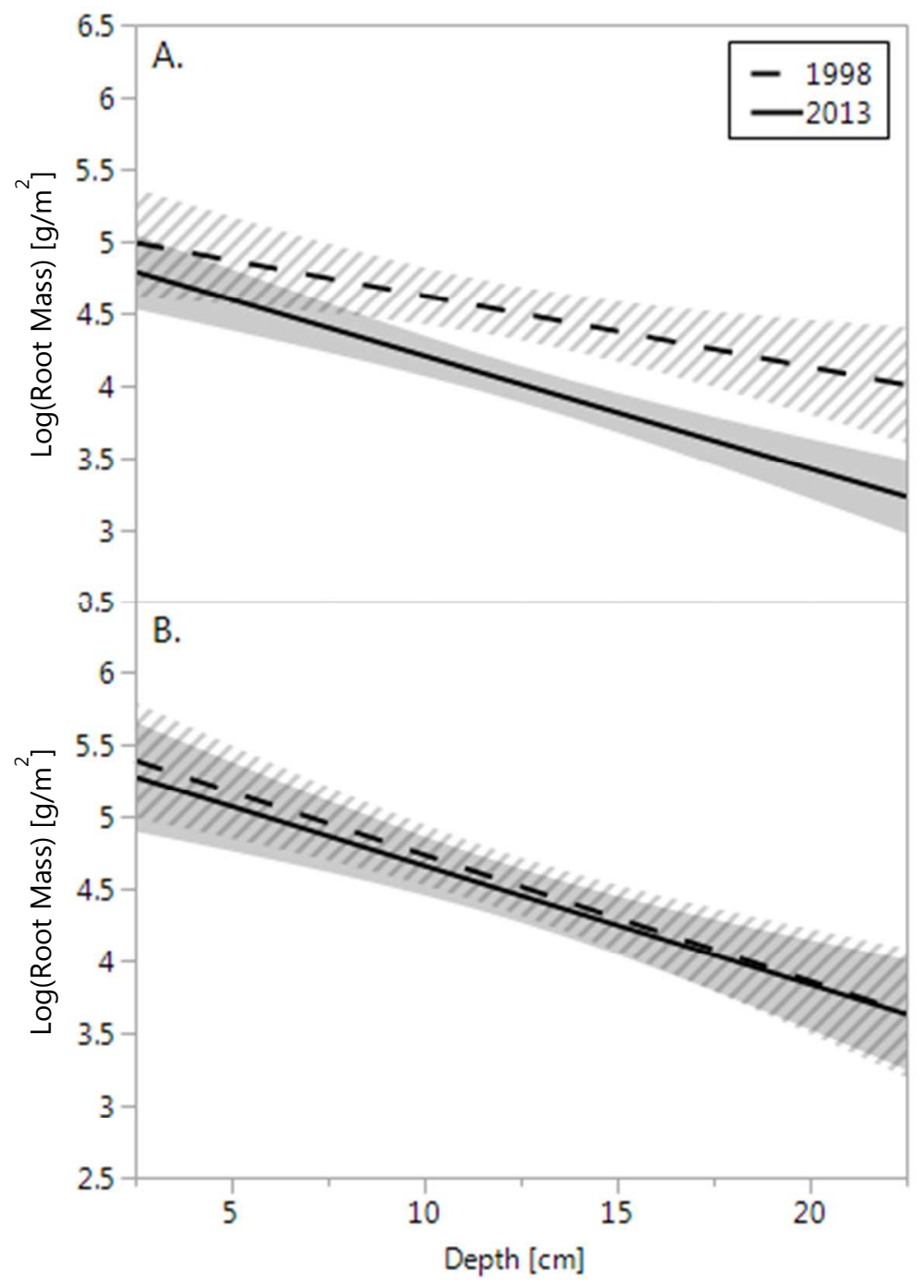

